\title{
Enhancing Doctoral Completion in Women: Evidence From a Qualitative Study of a Unique Federally Funded Program
}

\author{
Sandra P. Thomas \\ Professor and Chair, PhD program, College of Nursing \\ University of Tennessee, Knoxville \\ Donna Drake-Clark \\ Associate Professor and Program Director, Master of Science in Management-HRM \\ Specialization \\ University of Maryland University College \\ Maureen Grasso \\ Dean, Graduate School \\ The University of Georgia \\ Trudy Banta \\ Professor of Higher Education and Senior Advisor to the Chancellor \\ Indiana University-Purdue University Indianapolis
}

In an era where campus environments were often unwelcoming to women, and there were few women role models, an innovative program funded by the National Institute of Education produced 100\% completion by female and minority doctoral students. At a 25-year reunion, the graduates reflected on their program experiences and careers. Reflections were audiotaped and subjected to thematic narrative analysis. Five themes were identified through the assistance of a large interdisciplinary interpretive group: Freedom to Widen Horizons, We Were Kindred Souls, Women Who Wanted Us to Succeed, It Was a Gift, and Paying it Forward. Findings of the study are highly relevant today, given the persistence of sexism in academia, the underrepresentation of women among holders of doctoral degrees, and the need to better prepare women for faculty and leadership roles.

Correspondence concerning this article should be addressed to Sandra P. Thomas, sthomas@utk.edu. 
The campus environments encountered by women and minority graduate students in the 1970s were often unaccommodating, even hostile, particularly for minority women (Aguirre, 2000; Johnson-Bailey, Valentine, Cervero, \& Bowles, 2008, 2009; Moody, 1988; Trower \& Chait, 2002). Schetlin (1975, p. 104) described "an administrative world of unreason in which prescribed sex roles, myth, stereotype, and unexamined assumptions predominate," which she compared to Lewis Carroll's Wonderland. Hall and Sandler (1982) described the climate for women in college classrooms as "chilly" and noted that faculty attitudes and behaviors, along with the institution's culture, created this climate. Women faculty felt excluded from interactions with their male colleagues (White, 1970), while women students were often advised to lower their expectations and seek less taxing majors (Hall \& Sandler, 1982). Women who were advanced $\mathrm{PhD}$ candidates and recent graduates described isolation and pain during graduate school, as well as explicit sexual harassment and exploitation by professors (Jensen, 1982).

Not surprisingly, attrition of female doctoral students was high in this climate of deeply ingrained sexism. Yet a 100\% completion rate was achieved by a unique federally funded demonstration project specifically designed to foster academic success and leadership development in women and minorities. This qualitative study chronicles the experiences, both as doctoral students and afterward, of women who participated in this project in the late 1970s and early 1980s. The project, funded by the National Institute of Education (NIE), deserves careful attention because women and minorities still have higher attrition rates and take longer to earn graduate degrees than do White men (Council of Graduate Schools [CGS], 2004, 2008a, 2008b; Nettles \& Millett, 2006; Smallwood, 2004). Furthermore, the atmosphere for women in higher education is still described as "negative" and "chilly" in recent journal articles (Gardner, 2012; Thayer-Bacon, 2011), and male domination of faculty and administrative positions continues (Glazer-Raymo, 2008). Therefore, formidable challenges for women still exist. Before we listen to the voices of the women who participated in the NIE program, a brief review of selected literature on attrition and retention is in order.

\section{Attrition and Retention at the Graduate Level}

Attrition and retention at the graduate level were underresearched phenomena until the 1990s and are still inadequately understood (CGS, 2008a, 2008b; Girves \& Wemmerus, 1988; Golde, 2005). According to Nettles and Millett (2006, p. 18), attrition from doctoral programs hovers around 50\% in 
most studies, representing a "vexing issue for higher education.” Lovitts (2001) found that responsibility for doctoral student attrition was rarely placed on the academic system. Instead, administrators, faculty, and former students all tended to blame the students themselves for their departure. Lovitts attributed students' departure to failure to become integrated within their departments. Students lacked information about the nature of doctoral study and how to navigate the system successfully, felt an absence of community, expressed disappointment with the learning experience, and cited an unsatisfactory advisor relationship.

Golde (2005) compared the experiences of students in four departments at a Midwestern university. Six themes contributing to attrition were discovered: (a) research practices not matched with student's strengths, (b) poor fit of expectations between student and department, (c) mismatch between student and advisor, (d) student perception that research faculty life is incompatible with personal goals, (e) student perception that job market is poor, and (f) structural isolation of students.

In a meta-synthesis of research on doctoral student attrition, Bair and Haworth (2005) identified additional reasons for departure of students, including departmental culture, size of student cohort, and dissertation difficulty. Notably, demographic variables and standard indicators of academic achievement were not useful predictors of attrition. The researchers called for qualitative case studies and greater attention to the viewpoints of students themselves.

Viewpoints of students were elicited in the oft-cited survey by Nettles and Millett (2006), the largest study of doctoral students ever conducted. More than 9,000 doctoral students representing 21 institutions and 11 fields of study responded to an 88-item survey. The researchers discovered considerable variability among the 11 disciplines in student satisfaction, speed of degree completion, research productivity, and other aspects of doctoral experience. Among all students, research productivity (e.g., publishing, presenting, grant-writing) was positively related to degree completion. In fact, Nettles and Millett (2006, p. 199) concluded that there was "nothing more important as a predictor" than research productivity. Having a mentor also was positively related to degree completion, but one-third of the sample did not have one.

Building upon earlier work showing the importance of departmental culture, Gardner's (2009) research identified "high completion" departments and "low completion" departments. Faculty in the former (e.g., psychology, communication) described a culture of camaraderie with students, mutual respect, and caring for one another. In contrast, faculty in the latter (e.g., computer 
science, engineering) spoke little about supportive culture and student success was attributed to qualities inherent in the doctoral students themselves (intelligence, propensity for hard work).

Many sponsored programs designed to reduce doctoral attrition (e.g., Ford Foundation, Danforth Foundation, National Defense Education Act Fellowships) have had poor rates of success-that is, fellows did not have higher degree completion than nonfellows (Bowen \& Rudenstein, 1992). The Mellon Foundation's Graduate Education Initiative did reduce doctoral attrition through financial support of students, improvement of doctoral advising, clarity of communication about program requirements, and encouragement regarding prompt dissertation completion (Ehrenberg, Jakubson, Groen, So, $\&$ Price, 2007). However, gender issues were not discussed in the report of the study findings. In fact, insufficient attention has been paid to gender in this body of literature, although increased attention has been given to racial minorities. Nettles and Millett (2006) noted, "The research literature on the experience of women doctoral students is sparse" (p. 217).

In summary, the aforementioned literature illuminates various facets of the doctoral experience that are barriers or facilitators to doctoral degree completion, but fails to explain why women are more likely than men to leave PhD programs. Despite Bair and Haworth's (2005) call for more qualitative research, which might permit women's voices to be heard, seminal studies such as that of Nettles and Millett (2006) have relied on quantitative survey methodology. Gardner's (2009) study was qualitative, but focused on faculty perceptions, not students', and did not explore gender. Indications that sexism continues in higher education can be found in Nettles and Millett's (2006) study report: Men in all fields were more likely to (a) have a same-sex advisor, (b) report more social interaction with their faculty, and (c) rate faculty more favorably, suggesting "the continuing existence of the 'old boys' club'" (p. 218) that has always placed women at a disadvantage. The present qualitative study contributes to the literature by revealing how an innovative program enabled women to survive, and thrive, in an era that was even more sexist and discouraging than the data collection period of the Nettles and Millett investigation.

\section{Method}

The purpose of this study was to identify and describe the salient experiences of the White and minority women who participated in the demonstration project funded by NIE. Because there was only one male participant, this research focuses on the experiences of the women in the program. The pro- 
tocol used in this study was approved through the institutional review board of the third author's university. Narrative methodology (Riessman, 2008) was chosen because it not only invites interviewees to describe their individual experiences, but also includes examination of the historical, cultural, and/or political factors that influence participants' narratives (Riessman, 2008). Context is a critical element for full appreciation of the stories that are told. Therefore, we turn now to examination of the historical context of the NIE demonstration project.

\section{Historical Context for the NIE Project}

Although sex discrimination is currently the most commonly filed charge with the Equal Employment Opportunity Commission (U.S. Equal Employment Opportunity Commission, 2006), contemporary readers may not be fully cognizant of the national climate of the 1970s for women. In 1972, only $21 \%$ of faculty members were women (U.S. Department of Education, 1991). There were no women in U.S. cabinet positions, no female Supreme Court Justices, and no female network news anchors. Only 10\% of law and medical degrees were earned by women, and only six of 421 tenured faculty at Harvard were women (Gibbs, 2009). The average salary for women faculty in all ranks in $1972-73$ was $\$ 11,925$, compared to $\$ 14,415$ for men (U.S. Department of Education, 1991). A 1977 study indicated that although there had been a significant increase in the number of college courses dealing with sex roles, these courses tended to be taught by nontenured faculty using sexist course materials (Clark, 1977). In the corporate world, Kanter's (1977) classic study detailed the discrimination and isolation experienced by the few women in management positions. In the popular press, several books were published giving women advice on how to survive and succeed in business (Halcomb, 1979; Pinkstaff \& Wilkinson, 1979; Williams, 1977).

During the years of the NIE Fellows program, 1979 to 1982, most university departments were dominated by men, who were much more likely than women to be tenured full professors (Clark, 1977). These male professors were often autocratic with female advisees and some expected sexual favors as well as unpaid labor on their research. Sexism and sexual harassment were widespread, both in the university context and in the larger society (Clark, 1977; Gray, 1977; Hall \& Sandler, 1982). Yet, as noted by Pinkstaff and Wilkinson (1979), sexual harassment experiences were often considered to be figments of the imagination of a few neurotic women. In a study of graduate students in psychology, $40 \%$ of women vs. $12 \%$ of men believed that faculty discrimi- 
nated on the basis of sex (Brodsky, 1974). Female students reported fewer opportunities to participate in and publish research and to teach or supervise students; they experienced less encouragement to meet scholars outside the department; they were excluded from course-related activities such as field trips; and they had difficulty finding mentors (Brodsky, 1974; Hall \& Sandler, 1982; Madsen, 2008).

In addition to sexist treatment by male professors and supervisors, women of the 70s and 80s sometimes experienced passive-aggressive undermining by female superiors (Queen Bee Syndrome) and by their own female peers (horizontal violence). Queen Bees were women who had attained high-status positions and perceived other women as threats; therefore, they sabotaged the efforts of other women to reach the senior level (Camussi \& Leccardi, 2005; Joel, 1994; Williams, 1977). Horizontal violence (Freire, 1970) is a phenomenon that occurs when individuals who are oppressed take their resultant anger out on each other, because it cannot be vented upwardly at those in power. Examples of this phenomenon include destructive gossip and backstabbing.

\section{Genesis and Implementation of the NIE Project}

Faculty at a large southern research university, recognizing the need to provide special encouragement to women and minorities to pursue and complete doctoral degrees, developed and submitted a grant proposal to NIE in 1978. The proposal involved four groups of participants: predoctoral students, postdoctoral educators in local education agencies or community agencies, junior faculty, and senior faculty who served as mentors and directors of the research teams that developed as a result of the cross-group collaboration. It is important to note that most of the junior and senior faculty were themselves minorities and women.

The project was funded and began in the summer of 1979 with the selection of the first six predoctoral students (hereafter called "NIE Fellows"). Over the 3 years for which the project was funded, a total of 18 Fellows participated. All but one were women; five were African American. These Fellows received full tuition plus a stipend, funding that allowed them to pursue doctoral study full time. An important component of the program, designed to promote acquisition of leadership skills, was the opportunity for Fellows to manage their own project. The first group of Fellows developed selection criteria and conducted interviews to choose the Fellows for subsequent classes. The Fellows elected officers, scheduled and conducted meetings, and developed the quarterly progress reports NIE required. 
The NIE-sponsored program included special workshops and minicourses for all four levels of participants. Topics for training modules included preparing grant proposals, conducting research and evaluation studies, analyzing data, preparing reports, writing for publication, making presentations, and managing grants and contracts. NIE funds paid university faculty, as well as external experts, to conduct these training events.

Unlike their peers whose research experience was often narrowly confined to the dissertation, the NIE Fellows were involved in research throughout their program of study. The senior faculty, junior faculty, and postdoctoral educators defined some of the areas of research in which the NIE Fellows initially were involved. As the students progressed, increasingly they identified their own topics and relied on mentors within the project structure to assist with the research, data analysis, and report preparation. Mentors also suggested avenues for presenting the research at conferences and publishing it in appropriate journals. All of the Fellows made multiple conference presentations before they graduated, and many had publications. Leadership development was fostered through student internships (both on and off campus) with a variety of administrative personnel, and through introductions to prominent female and minority leaders in the students' fields of interest who could serve as role models.

\section{Data Collection}

A reunion of the NIE Fellows in 2007 brought together ten of the 15 surviving women graduates to talk with the project administrator about their experiences in the program and their subsequent career stories (three others had planned to attend but were prevented from doing so by last-minute personal or family emergencies). At their own expense, the women traveled back to the project site for the weekend reunion. An audiotaped discussion, more than 2 hours in length, was transcribed for analysis. The conversation was unstructured and other than a brief introductory question posed by one of the authors of this paper, no interview protocol was used. Three authors of this paper had been involved in the NIE project and participated in the group discussion at the reunion; the other author had no involvement in the project, contributing only to manuscript preparation. Additional data were obtained from an online questionnaire consisting of six open-ended questions:

1. In what ways did the NIE Fellows program enable you to complete your graduate degree?

2. What challenges did you face during your graduate studies? 
3. How would you describe your relationships with faculty at [university]?

4. How would you describe your relationships with peers at [university]?

5. For you, what were the most positive aspects of being an NIE Fellow?

6. What would have made your experience as an NIE Fellow better?

Participants also were asked about their current job titles and salaries, the impact of the program on their first jobs and subsequent careers, and demographic information. In addition to the questionnaire responses and the transcript of the group discussion, the research team reviewed a variety of archival program documents.

\section{Demographic Characteristics of Participants}

The women in this study were born between 1940 and 1951. All have enjoyed a high level of career success. Job titles include academic dean, professor, founder and president of a consulting firm, therapist, director of human resources, and business owner. Fields of study in which their doctorates were earned include education (educational administration, educational leadership, educational psychology), child and family studies, psychology, and textile science. To protect the identities of the women in this small and unique sample, demographic characteristics such as age, race, and specific discipline are not linked to the verbatim quotes that we use to illustrate the themes. Of the 18 Fellows, 13 were White and 5 were African American. All but one of the Fellows were women.

\section{Data Analysis}

To analyze the audiotaped reflections of the ten women who came to the reunion, thematic narrative analysis (Riessman, 2008) was used. This approach is considered appropriate for a group meeting such as the NIE Fellows' reunion. The advantages of group meetings are that (a) stories shared in such settings are less likely to have been told in the same manner before; and (b) speakers often expand upon or correct what others have said (Riessman, 2008). Because the NIE Fellows had not been together for some 25-27 years, and had never reflected together about their doctoral experiences, their stories were completely unrehearsed. Commonalities among experiences soon became evident, however. The transcript included many instances of group members adding to stories or affirming key memories of other participants with exclamations such as "Oh, yes!" "Right!” and "Absolutely!" 
Assistance with data analysis was provided by an ongoing interdisciplinary interpretive group that has been meeting weekly at a large southern research university since 1994 . Members of the group signed confidentiality agreements asserting that they would not discuss contents of transcripts outside the weekly meetings, during which transcripts from qualitative research projects were read aloud. Group members were not aware of the location of the NIE Fellows program, or that the group's coleader had been an NIE Fellow.

A total of 10 readers from disciplines such as psychology, education, nursing, and political science participated in the first set of sessions devoted to the transcript of the group discussion by the NIE Fellows. Three 2-hour meetings were required because of the length of the transcript. After all identifying information had been removed, the transcript was read aloud and thematized by the interdisciplinary interpretive group. Words and phrases that seemed to shed light on the meaning of participants' experiences were discussed, and preliminary themes and patterns were identified and labeled. Labels were often modified as the text presented new evidence that cast earlier conclusions in a different light. This iterative group process was recorded in notes kept by the coleader, providing an audit trail. After each of the three group analytic sessions, the preliminary themes were discussed among the research team members via telephone conferencing. Responses to the open-ended questions on the online survey were handled in the same manner. Over the course of four sessions devoted to the survey data, 25 readers from a variety of disciplines participated. Alternative interpretations of the data were proposed, followed by close scrutiny of participants' responses for supportive evidence of these interpretations. During the final session, members of the interpretive group achieved consensus that the themes derived from both sources were congruent and could be combined.

\section{Findings}

Five themes were identified: (a) Freedom to Widen Horizons, (b) We Were Kindred Souls, (c) Women Who Wanted Us to Succeed, (d) It Was a Gift, and (e) Paying it Forward. The names of the themes were closely aligned with actual words used by study participants. Each theme is described below and illustrated by excerpts from the online survey and the narratives of the NIE Fellows who attended the 2007 reunion. 


\section{Theme One: "Freedom to Widen Horizons"}

Study participants used adjectives such as "exhilarating" and "exciting" to describe their participation in the NIE program as a heady time of immersion and focus. They were free to be full-time PhD students, a response heavily emphasized in the recollections of several women:

When this opportunity came along, it was great because I had been trying to work full time and go to school full time, and I was going to the counseling center to get rid of the migraines and the whole bit.

The fellowship also permitted the pursuit of internships, externships, and cross-discipline research opportunities that widened the students' horizons. One woman's words aptly depict this theme: "It wasn't like you had to TA a class or work for somebody else's research. . . . So there was wonderful freedom and flexibility. ... You had the freedom to explore, and think, and to do research in other areas." It is important to note that this type of research experience "in other areas" is very different from traditional research assistantships in which students are immersed in the faculty's research agenda. Here, the students could pursue interests of their own. For example, a group of students generated their own project about stress of women in dual-career families, found mentors with the appropriate expertise in instrument development, and eventually reported their completed research at a national conference and in several journal articles.

Participants viewed their hands-on experience in leadership roles as invaluable to their later careers. One Fellow interned in the office of the university's vice president for government relations (the university's chief lobbyist in Washington), and another served as an intern with the affirmative action coordinator. Another Fellow spent several weeks at IBM headquarters in New York, observing the corporate child care program there; she wrote that "the internship experience with IBM in New York set the stage for moving into the business arena and having the skills to talk to both the for-profit and nonprofit world." A woman who interned in Washington with the university's vice president for research said, "This paid off later when I began writing grants. I was not intimidated by our research office. . . . That gave me the confidence to swim with the sharks and barracudas." Another woman, recalling that she was given the opportunity to plan a whole workshop for students at a national conference, pointed out that "the [NIE] grant changed my motivation from getting finished quick to 'how are you going to use what you learned'?" 
Freedom to manage the project itself was granted by the project director, who had a philosophy of "growing people." As described by one participant, "Her decision to release the control of the program's structure, evaluation, and midcourse correction to us, the Fellows, was such a gift. We learned much more than if we had been provided a template to walk through." Another participant echoed, "I did not anticipate it being nearly that self-directed, and it was great!" The positions of chair, scribe, and budget monitor rotated among the students each quarter. One woman, now an academic dean, recalled what it was like to be selected as the chair:

I was told [by the project director] "Your peers see you as a leader, so we would like for you to step in as chair.". . I I was like, "Oh my God, I don't even know what I am doing here.” But that vote of confidence made all the difference. ... When you realize that people see something in you that you might not see in yourself, you begin to trust those people. . . . You begin to say, "Well, there must be something here." And that's always been in the back of my mind, and that has given me the confidence to step forward in many other situations throughout my career.

Leadership experiences in roles other than chair were abundant. For example, one student would assume the responsibility of arranging workshops and sack-lunch colloquia about topics such as finance in higher education, women in government, communication and proxemics, Black women's issues, and preparing for job interviews. Another student would edit the newsletter. The students created a logo that was used on their business cards, newsletters, and other printed materials. Suggestions for consultants, research collaborators, and internship experiences were generated by the students themselves and submitted to the project director. Students made a number of presentations about the NIE project at professional conferences, in collaboration with the project director and/or various faculty mentors. Decisions about allocating funds for conference travel were made by the students themselves. In consultation with an external evaluation expert the Fellows designed and carried out an evaluation of the program.

One might suppose that these project-related responsibilities could become burdensome, given that the NIE Fellows also carried a full academic course load, but the following quotes negate that supposition:

It was a fun experience. It really didn't feel like work. I remember writing presentations and preparing them, but it didn't feel like work.

[Second speaker responds]: You're right, it didn't feel like work. 


\section{Theme Two: "We Were Kindred Souls"}

Participants spoke fondly of the bonding with peers that occurred during the course of the project, a feature that was especially appreciated by students returning to academia later in life than traditional doctoral students. For example, one participant wrote, "The NIE program provided me a wonderful peer group because most of the Fellows were 'older students,' i.e., in their 30s and 40s, like me. The Fellows were all bright and ambitious, so we were kindred souls." It was also important that the kindred souls were female. Speaking of her colleagues, another participant said, "They were a group of capable, competent, neat, smart women. . . Being a smart woman is not always appreciated. And to have other smart women around was really, really wonderful." Some contrasted the collegiality among the NIE Fellows with "the backstabbing that you sometimes see today" (i.e., the horizontal violence described in recent papers by Jones and Palmer [2011] and Thayer-Bacon [2011]). Collaboration, rather than competition, was emphasized in the following comments:

The [NIE] grant enabled me to branch out and get to know my peers. I felt we were supportive of each other, as opposed to being in competition.

The extraordinarily collaborative experience of the Fellows program impacted everything I have done since.

Although few racial tensions were discussed by the participants, some of the White women had not previously worked closely with Black women. One of the Black participants noted that at least one White student had initially resented having to share a hotel room with a Black woman during a conference. She also noted that there were some negative feelings toward a student who was in a mixed-race relationship. However, in her questionnaire response she credited the program for the opportunities it provided for women of different races to work together:

I shall forever be grateful to the program. I only regret that the federal support for the program ended with a change in administration in the government. If the program hadn't been dropped, I believe colleges and universities would be more diverse today, and better able to serve students because of it.

Several participants elaborated on the way their "secret club" prepared them for career success: 
It was a safe and supportive group to be in. . . . My husband thought I was part of a "secret club." It was not a secret, but it was a great club. It laid the foundations for me as an administrator.

I loved doing research with the other Fellows. . . . I also loved the collaborative writing I did with [name of peer], which probably served as the genesis of later successful writing for publication.

\section{Theme Three: "Women Who Wanted Us to Succeed"}

Faculty and postdoctoral associates provided mentoring for the women in the program. The female mentors, in the words of one participant, "opened their arms to us and they really did mentor us." This mentoring was especially beneficial to the Black female doctoral students because Black women often have great difficulty finding mentors (Madsen, 2008; Woods, 2001). The support, role modeling, and mentoring that Fellows received from the female project mentors was crucial, given the widespread sexism and sexual harassment of the era. Two examples will suffice to illustrate the sexism experienced by NIE Fellows. In the first, a woman who wore a sundress in class was admonished by a male professor to wear more conservative clothing because he could focus on nothing but her breasts. He told the woman that she would never be successful in her academic career unless she began to dress like a female administrator who wore shapeless suits with long skirts, sensible oxford shoes, and her hair in a bun. In the second episode, a male professor exposed himself to an NIE Fellow during a conference trip and raged at her afterward because she did not respond to his advances.

The NIE project mentors created an alternative to the "old boys club" that often existed in the Fellows' own departments. The following three quotes are illustrative:

Before I had the NIE fellowship I was your stereotypical female graduate student, in that I had four male committee members who guided my life at that point. .. . They were not role models, they were not necessarily very strong researchers, they were not supportive.

I was receiving my degree in a department that had no female faculty . . . I did not feel that many of the faculty "got it," in terms of diversifying the field.

The cross-discipline association with women from other departments was critical. 
Because having a baby while pursuing doctoral study tended to diminish women's acceptance by men during the era of the program, one participant expressed her gratitude for the NIE program's "supportive atmosphere for women in my stage of life and family; it truly made it possible for me to continue ... even with a new baby to care for." Other participants elaborated on the "different world" and "different assertiveness" the project facilitated:

In my department, we had only two female faculty members, so interaction with females was not a part of the reality. When I got the fellowship, it was like a whole different world. I was among women. Being with this group of women was empowering.

We had a different assertiveness about us, or a different confidence. Second speaker adds:

We were validated in a way we didn't have to fight for it.

[First speaker resumes]: . . and that was very different.

Participants spoke of their female mentors as "strong, intelligent women, women who wanted us to succeed." This is the opposite of the Queen Bee behaviors described in the 1970s literature (e.g., Williams, 1977). Within the NIE project, senior women were very supportive of junior women. This theme was aptly summarized as follows: "This was women facilitating, supporting women, encouraging women ... women bringing women and giving women opportunity to advance and do better."

\section{Theme Four: "It Was a Gift"}

The financial support provided by the federal funding was often mentioned in participant narratives and in the questionnaire responses. One participant explicitly credited her timely $\mathrm{PhD}$ completion to the funding, writing that "The program provided the necessary funding my final year. If it were not for this program, I would not have been able to finish my $\mathrm{PhD}$." She went on to describe an unfortunate situation with an authoritarian male dissertation chair who she needed to "divorce." At one time, she had despaired of completing her degree in timely fashion after her chair told her: "You will work and finish when I tell you that you are finished." She concluded her story by saying "Being part of this program allowed me to change the research focus of my dissertation, change chairs, and move forward and complete the degree on time." 
One participant wrote, "The financial aid allowed me to work on my dissertation full time." Another laughingly recalled, "If I had not gotten that money so I could become a full-time student, I probably would still be taking one course at a time. Absolutely that made the difference. To be full time is an incredible privilege."

Gratitude for the money that opened many doors was evident in the following excerpts from the data:

It was a gift to have time to devote energy to the doctoral work. The travel allowance was also a gift, as it enabled us to see beyond our own campus, interact with professionals from other universities and colleges, and experience being a presenter at national and regional conferences.

First, and foremost, the financial support enabled me to stop working for 1 fabulous year of full-time immersion in $\mathrm{PhD}$ study. After that, I did have to work part time once again because finances were tight. The travel support enabled me to make my first paper presentations at national conferences.

The theme "It Was a Gift" provides evidence of the importance of financial support, not only in increasing doctoral completion, but also in providing opportunities to grow as a professional scholar. The "gift" was an important investment in the lives of the Fellows and the return on that investment has not only made an impact on the individual lives of the Fellows, but also more importantly as a public good to our society. The return on investment is apparent in the next theme, "Paying it Forward."

\section{Theme Five: "Paying it Forward"}

The NIE Fellows unanimously voiced a sense of responsibility to "pay forward" to mentees what they had been privileged to experience as doctoral students. Their stories showed how they have acted as mentors to subsequent cohorts of students. As one participant related, "I hear over and over again, 'you are a wonderful mentor, you have been so supportive, so helpful.' I learned it all from this group." Another wrote, "It was an incredible experience, one that I remember today and give forward to my students by providing them with funding and the freedom to be curious, and to develop into emerging leaders."

The idea of "Paying it Forward" is consistent with Madsen's (2008) finding that a desire to help others develop and succeed motivates women university presidents to take on leadership roles. The NIE Fellows do this by one-on-one 
mentoring ("growing people") as well as by creating structures to perpetuate what they do after they are gone. For example, one participant currently directs her university's diversity initiative; in the past, she has cochaired an antiharassment team and started a support service for gay, bisexual, and transgender students. Another wrote of her involvement in "efforts to undo racism in education and end the achievement gap." The following three quotes illustrate this theme:

We were to be teachers, we were to be researchers, we were to do something in the community. We have to mentor those that follow, and I see that as a privilege.

You need to provide those qualities that would make another individual want to emulate some of the things you do...openness and willingness to be a mentor to others ... you need to give back.

I see myself in a mentoring role, and I think [that] comes from being in that supportive environment. . . . I was always the one who would take on a student.

\section{Discussion}

Women continue to be underrepresented among holders of doctoral degrees; in 2000, women represented $52 \%$ of American adults but a mere 29.5\% of individuals with doctorates (Nettles \& Millett, 2006). Although more minorities are earning doctoral degrees, the gains are slow and small. In $1981,8 \%$ of doctoral degrees were awarded to minority students; by 2000, the percentage was only 13\% (Nettles \& Millett, 2006). Additionally concerning is the continued underrepresentation of women and minorities among university faculty. Much work remains to achieve adequate representation of women and minorities in many disciplines, especially the science, technology, engineering, and mathematics (STEM) disciplines. Although more women are entering science and engineering, O'Brien and Hapgood (2012) pointed out that these women leave the "academic jungle" at a higher rate than men and perform worse on quantitative indicators of research performance, such as publications. Despite the gains made since the Civil Rights Movement and the Women's Liberation Movement, it is clear that effective measures to enhance doctoral completion and career success of women and minorities are still needed. The success of the NIE program in the 1980s would be notable even today but is truly remarkable given the sociocultural context of its time. 
In examining the accomplishments of the NIE Fellows program in retrospect, one can identify the presence of the five conditions identified by CGS (2004, 2008c) in its PhD Completion Project: (a) selection of students who understand the demands of graduate programs, (b) attention to orientation of the students who are admitted, (c) respectful working relationships between faculty mentors and students, (e) peer-to-peer mutual support, and (f) financial support. Clearly, these conditions were instrumental in the success of the NIE program, which resulted in $100 \%$ completion for the participants. However, at the time the program was developed, the project director and participating faculty had no empirical evidence to guide the creation of the five conditions since very little literature existed on the topic of doctoral program completion until the 1990s.

While the NIE Fellows had already met the first two conditions identified by CGS prior to the start of the program - that is, they had applied and been admitted to the university for doctoral study - they had to meet these two conditions again, at even higher levels, for acceptance as NIE Fellows. In the first year, faculty recruited participants and established the selection/ admission criteria for the project. In the recruitment process, faculty members gave prospective applicants realistic information about the academic demands and funding associated with the program. During the following 2 years, the NIE participants themselves assisted in recruiting participants and developed the rigorous selection/admission criteria. Fellows were selected from various disciplines across the university.

Because the NIE Fellows were from different disciplines, research modes, processes, and procedures were different; therefore, discipline-specific mentoring was not directly addressed in the program. However, general research mentoring and other mentoring, such as how to navigate the doctoral education system and how to write grants/manuscripts, were integral parts of the program. Because the Fellows were involved in research throughout their studies, they not only acquired the skills to successfully complete their dissertations but also achieved the research productivity so heavily emphasized by Nettles and Millett (2006) as a predictor of doctoral program completion. In addition, the program structure featured multiple opportunities for peer-topeer support. Finally, generous funding for tuition plus stipends and travel to conferences and internships provided the essential financial support that most of the students needed to build an impressive curriculum vitae and ultimately complete their doctoral studies.

To those who may question whether our findings are relevant 30 years after the program's end, a review of recent literature documents persistence of 
sexism and bias in academia (although more subtle and perhaps unconscious) as well as an urgent need to prepare more women for leadership (Gerdes, 2006; Morahan, Rosen, Richman, \& Gleason, 2011; Valerio, 2006). Current literature also documents the continued presence of horizontal violence among women in higher education (Gardner, 2012; Jones \& Palmer, 2011; Thayer-Bacon, 2011), behavior that sharply contrasts with the woman-towoman mentoring described by the NIE Fellows. Women's own words vividly described what it was like to be mentored by women who "opened their arms" and created a "safe and supportive" atmosphere in which they could flourish. This supportive milieu is similar to descriptors of "high completion" departments in Gardner's (2009) study. It should be noted here that the members of the interpretive group who read and thematized the transcripts expressed envy when reading the women's words. Most of the faculty and doctoral students comprising the interpretive group said they did not have comparable experiences of support and mentoring. Recall that one-third of the respondents in the massive doctoral student survey by Nettles and Millett (2006) reported lack of a mentor.

The ability to pay for graduate education continues to be a significant concern for minority and women students (Gasman, Hirschfeld, \& Vultaggio, 2008; Moyer, Salovey, \& Casey-Cannon, 1999; St. John, Paulsen, \& Carter, 2005). Unlike the NIE Fellows who received generous financial support, African American graduate students studied by Gasman, Hirschfeld, and Vultaggio (2008) reported that financial struggles affected their ability to focus on their studies. Lack of funds to attend and present at conferences caused the students to miss prime networking opportunities, which subsequently hindered their search for jobs.

This study demonstrates the importance of federal government support of education through fellowships and funding for programs. The federal funding made possible all of the enrichment activities the NIE Fellows experienced, from workshops and minicourses, to off-campus externships, to travel to conferences to present research findings. However, as noted by St. John, Paulsen, and Carter (2005), the federal government has reduced its commitment to providing need-based financial aid.

\section{Limitations}

No claim is made that the experiences of the women and minorities in this study are representative of doctoral students in the late 1970s and 1980s. Re- 
grettably, the sample contained no students in the STEM disciplines, although application forms for the fellowship had been widely distributed throughout the university. The NIE program is best viewed as a unique case study. It is beyond the scope of this paper to evaluate similarities and/or dissimilarities between the NIE program and current federal programs designed to support women and minorities. Nevertheless, important lessons about enhancing doctoral completion can be drawn from these data.

\section{Conclusions}

The findings of this study support three conclusions: (a) the conditions described by CGS (2004) as optimal for doctoral completion did help women and minorities complete their degrees and can be applied in other doctoral programs; (b) freedom to widen horizons, mentoring (especially woman-towoman mentoring), peer support, and financial assistance were perceived by study participants as vital to their successful completion of doctoral studies; and (c) real-life, hands-on experiences in collaborative research and leadership roles prepared the students for career success. Unlike most research about doctoral education (Golde, 2005), this study describes an innovative, successful program that can serve as a model for other universities.

In an era where there were few women role models-women constituted only $35 \%$ of the enrollment in graduate programs, and campus environments were unwelcoming to women-the NIE Fellows program demonstrated that providing women with a variety of formal and informal learning experiences in an atmosphere of peer, faculty, and financial support prepared them for successful careers in higher education, consulting, and other fields. Unlike the "Queen Bees" of the past who sabotaged junior women, the NIE Fellows were committed to "paying it forward" by mentoring as they had been mentored. In their subsequent leadership roles, they were involved in combating racism, sexism, and sexual harassment.

The results of this qualitative study increase and reaffirm our understanding of key elements that facilitate doctoral completion. The NIE Fellows demonstration project enhanced the success of women and minorities in graduate school, and its $100 \%$ completion rate is eloquent testament to its effectiveness. The overall impact of the NIE Fellows program can be summarized by this quotation from our data:

When I listen to everybody's story, what becomes clear to me is that society has gained so much that they invested in us. . . In many different 
ways we have given so much in all our different fields, and all the different ways in which we contribute. That may not have been possible without the fellowship.

\section{References}

Aguirre, A. (2000). Women and minority faculty in the academic workplace: Recruitment, retention, and academic culture. ASHE-ERIC Higher Education Report, vol. 27, no. 6. San Francisco, CA: Jossey-Bass.

Bair, C. R., \& Haworth, J. G. (2005). Doctoral student attrition and persistence: A meta-synthesis of research. In J. C. Smart (Ed.), Higher education: Handbook of theory and research, vol. 19 (pp. 481-534). Dordrecht, Netherlands: Kluwer Academic Publishers.

Bowen, W. G., \& Rudenstine, N. L. (1992). In pursuit of the PhD. Princeton, NJ: Princeton University Press.

Brodsky, A. (1974). Women as graduate students. American Psychologist, 29(7), 523-526.

Camussi, E., \& Leccardi, C. (2005). Stereotypes of working women: The power of expectations. Social Science Information, 44(1), 113-140.

Clark, L. (1977). Fact and fantasy: A recent profile of women in academia. Peabody Journal of Education, 54(2), 103-109.

Council of Graduate Schools. (2004). Ph.D. completion and attrition: Policy, numbers, leadership and next steps. Washington, DC: Author.

Council of Graduate Schools. (2008a). Analysis of baseline demographic data from the Ph.D. completion project. Washington, DC: Author.

Council of Graduate Schools. (2008b). Analysis of baseline program data from the Ph.D. completion project. Washington, DC: Author.

Council of Graduate Schools PhD Completion Project. (2008c). Promising practices: Financial support. Retrieved from http://www.phdcompletion.org

Ehrenberg, R. G., Jakubson, G. H., Groen, J. A., \& Price, J. (2007). Inside the black box of doctoral education: What program characteristics influence doctoral students' attrition and graduation probabilities? Educational Evaluation and Policy Analysis, 29, 134-150.

Freire, P. (1970). Pedagogy of the oppressed. New York, NY: Seabury Press.

Gardner, S. (2009). Conceptualizing success in doctoral education: Perspectives of faculty in seven disciplines. The Review of Higher Education, 32, 383-406.

Gardner, S. (2012). "I couldn't wait to leave the toxic environment": A mixed methods study of women faculty satisfaction and departure from one re- 
search institution. NASPA Journal About Women in Higher Education, 5, 71-95.

Gasman, M., Hirschfeld, A., \& Vultaggio, J. (2008). "Difficult yet rewarding": The experiences of African American graduate students in education at an Ivy League institution. Journal of Diversity in Higher Education, 1(2), 126-138.

Gerdes, E. P. (2006). Women in higher education since 1970: The more things change, the more they stay the same. Advancing Women in Leadership Online Journal, 21, 1-20.

Gibbs, N. (2009). What women want now: A Time special report. Time, 174(16), 24-29.

Girves, J. E., \& Wemmerus, V. (1988). Developing models of graduate student degree progress. Journal of Higher Education, 59(2), 163-189.

Glazer-Raymo, J. (2008). Unfinished agendas: New and continuing gender challenges in higher education. Baltimore, MD: The Johns Hopkins Press.

Golde, C. M. (2005). The role of department and discipline in doctoral student attrition: Lessons from four departments. Journal of Higher Education, 76(6), 669-700.

Gray, M. G. (1977). The new executive woman: A guide to business success. New York, NY: Mentor.

Halcomb, R. (1979). Women making it: Patterns and profiles of success. New York, NY: Ballantine.

Hall, R. M., \& Sandler, B. R. (1982). The classroom climate: A chilly one for women? Washington, DC: Project on the Status and Education of Women, Association of American Colleges. ERIC Reproduction Service ED 215 626.

Jensen, K. (1982). Women's work and academic culture: Adaptations and confrontations. Higher Education, 11, 67-83.

Joel, L. A. (1994). Maybe a pot watcher, but never an ostrich. American Journal of Nursing, $94(4), 7$.

Johnson-Bailey, J., Valentine, T., Cervero, R. M., \& Bowles, T. A. (2008). Lean on me: The support experiences of Black graduate students. Journal of Negro Education, 77(4), 365-381.

Johnson-Bailey, J., Valentine, T., Cervero, R. M., \& Bowles, T. A. (2009). Rooted in the soil: The social experiences of black graduate students at a southern research university. Journal of Higher Education, 80(2), 178-203. Jones, S. J., \& Palmer, E. M. (2011). Glass ceilings and catfights: Career barriers for professional women in academia. Advancing Women in Leadership, 31, 189-198. 
Kanter, R. M. (1977). Men and women of the corporation. New York, NY: Basic Books.

Lovitts, B. (2001). Leaving the ivory tower: The causes and consequences of departure from doctoral study (1st ed.). New York, NY: Rowman and Littlefield.

Madsen, S. R. (2008). On becoming a woman leader: Learning from the experiences of university presidents. San Francisco, CA: Jossey-Bass.

Moody, C. D., Sr. (1988). Strategies for improving the representation of minority faculty in research universities. Peabody Journal of Education, 66(1), 77-90.

Morahan, P. S., Rosen, S. E., Richman, R. C., \& Gleason, K. A. (2011). The leadership continuum: A framework for organizational and individual assessment relative to the advancement of women physicians and scientists. Journal of Women's Health, 20, 387-396.

Moyer, A., Salovey, P., \& Casey-Cannon, S. (1999). Challenges facing female doctoral students and recent graduates. Psychology of Women Quarterly, 23, 607-630.

Nettles, M. T., \& Millett, C. M. (2006). Three magic letters: Getting to PhD. Baltimore, MD:

Johns Hopkins Press.

O’Brien, K. R., \& Hapgood, K. P. (2012). The academic jungle: Ecosystem modeling reveals why women are driven out of research. Oikos, 121, 9991004.

Pinkstaff, M. A., \& Wilkinson, A. B. (1979). Women at work: Overcoming the obstacles. Reading, MA: Addison-Wesley.

Riessman, C. K. (2008). Narrative methods for the human sciences. Thousand Oaks, CA: SAGE.

Schetlin, E. M. (1975, spring). Wonderland and the looking glass. Women in Administration: Journal of NAWDAC, 104-109.

Smallwood, S. (2004). Doctor dropout. The Chronicle of Higher Education, 50(19), A10-A12.

St. John, E. P., Paulsen, M. B., \& Carter, D. F. (2005). Diversity, college costs, and postsecondary opportunity: An examination of the financial nexus between college choice and persistence for African Americans and Whites. Journal of Higher Education, 76(5), 545-569.

Thayer-Bacon, B.J. (2011). Befriending (White) women faculty in higher education? Advancing Women in Leadership, 31(1), 22-33.

Trower, C. A., \& Chait, R. P. (2002, March-April). Faculty diversity: Too little for too long. Harvard Magazine, 104(4), 2-12.

U.S. Department of Education. (1991). Digest of education statistics 1990 (Na- 
tional Center for Education Statistics Publication No. 91-660). Washington, DC: U.S. Government Printing Office.

U.S. Equal Employment Opportunity Commission. (2006). Charge statistics FY 1992 through FY 2005. Retrieved from http://www.eeoc.gov/stats/ charges.html

Valerio, A. M. (2006). An action plan for developing women leaders. Leaders in Action, 26(5), 1-6.

White, M. S. (1970). Psychological and social barriers to women in science. Science, 170(3956), 413-416.

Williams, M. G. (1977). The new executive woman: A guide to business success. New York, NY: Mentor.

Woods, R. L. (2001). Invisible women: The experiences of Black female doctoral students at the University of Michigan. In R. O. Mabokela \& A. L. Green (Eds.), Sisters of the academy: Emergent black women scholars in higher education (pp. 105-115). Sterling, VA: Stylus. 